\title{
Effects of adding Magnesium Sulphate to Ropivacaine and Fentanyl for spinal anaesthesia
}

\author{
${ }^{1}$ Dr. Manjula R, ${ }^{2}$ Dr. Indumathi, ${ }^{3}$ Dr. Sangeetha C, \\ ${ }^{4}$ Dr. Vasundhara Vadaguru Mallikarjuna \\ ${ }^{1,2}$ (Associate Professor, Dept of Anaesthesiology, Adichunchunagiri Institute of Medical Sciences); \\ 3,4 (Post Graduate, Adichunchunagiri Institute of Medical Sciences);
}

\begin{abstract}
:
Objective: To compare the block characteristics and haemodynamic stability of intrathecal Ropivacaine and Fentanyl; with and without Magnesium as adjuvant for lower limb surgeries. Method: Sixty patients of ASA grade I and II coming for elective lower limb surgeries under spinal anaesthesia were randomly allocated into two groups with 30 patients in each group. Group F received Isobaric Ropivacaine $0.75 \%-2.4 m l+$ Fentanyl $20 \mu+0.2 \mathrm{ml} \mathrm{NS}$ and $\quad$ Group M received Isobaric ropivacaine $-2.4 \mathrm{ml}+$ Fentanyl $20 \mu+25 \%$ Magnesium Sulphate 0.2ml. Sensory and motor block characteristics were assessed by pin prick and modified Bromage scale respectively and haemodynamics were recorded. Results: Time to reach T10 dermatome was delayed in group M (4.23 $\pm 0.94 \mathrm{~min})$ compared to group $F(2.92 \pm 0.81 \mathrm{mins})$. The onset of motor block was also significantly delayed in group $M(4.63 \pm 0.85$ mins) than group $F(3.30 \pm 0.79$ mins). Duration of analgesia was higher in group $M$ and time for motor recovery was also delayed in group $M(p<0.001)$. Conclusion: Time for onset and recovery of sensory and motor block was delayed with intrathecal ropivacaine in combination with Fentanyl and Magnesium Sulphate as adjuvants than intrathecal Ropivacaine and fentanyl alone.
\end{abstract}

Key words: intrathecal injection, Ropivacaine, Fentanyl, Magnesium Sulphate.

\section{Introduction}

Spinal anesthesia is a widely used technique, providing a fast onset and dense sensory and motor blockade. Various intrathecal adjuvants have been used to improve the quality and the duration of spinal anesthesia. Ropivacaine is a newer local anaesthetic with lower risk of neurotoxicity and cardiotoxicity compared with bupivacaine and Lidocaine. ${ }^{(1,2,3)}$. Ropivacaine has been advocated as a drug with a shorter duration of motor block and prolonged sensory analgesia than bupivacaine. Prolongation of spinal anaesthesia is desirable both for long procedures and postoperative pain relief. Highly lipid soluble opiods have higher affinity for opiod receptors and improve the quality of intraoperative anesthesia and permit lower doses of local anaesthetics when used intrathecally. They provide faster onset and prolonged duration analgesia $(16,17,18)$ .Intrathecal opiods can cause pruritis, urinary retention, respiratory depression, nausea and vomiting as adverse effects. Thus addition of intrathecal magnesium sulphate has been used to study the effect of potentiation of

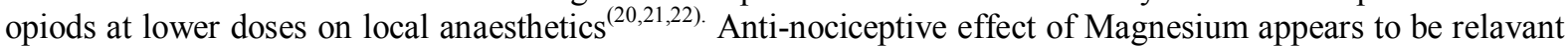
not only for chronic pain, but also in postoperative pain based on regulation of calcium influx into the cell. Magnesium blocks calcium influx and noncompetitively antagonizes NMDA channels ${ }^{(23,24,25.26,27)}$ and addition of magnesium sulphate improves postoperative analgesia.

\section{Methods}

A prospective randomised study was conducted at Adichunchanagiri Institute of Medical Sciences, B.G. Nagara, after obtaining written informed consent from 60 patients in the age group of 18 to 60 years. Patients of A S A grade 1 and 2 posted for elective lower limb surgeries were randomly selected and allocated into two groups. Group F received Isobaric Ropivacaine $-2.4 \mathrm{ml}+$ Fentanyl $20 \mu+0.2 \mathrm{ml} \mathrm{NS}$ and Group M received Isobaric Ropivacaine $-2.4 \mathrm{ml}+$ Fentanyl $20 \mu+0.2 \mathrm{ml}$ of $25 \%$ Magnesium Sulphate $(50 \mathrm{mg}$ ). All patients were preloaded with $500 \mathrm{ml} \mathrm{RL}$. With the patient in lateral position, subarachnoid block was performed at L3-L4 space with 23G spinal needle. After injection of drug, patients were placed supine.

Heart rate and blood pressure were recorded before intrathecal injection and 5 minutes after the intrathecal drug administration up to first half an hour and thereafter every 10 minutes till the end of the operation and at hourly interval after the end of the surgery. MAP lower than $60 \mathrm{~mm}$ of $\mathrm{Hg}$ or systolic BP less than 30\% from base line and HR less than 50 beats / min were treated with Inj. Ephedrine $6 \mathrm{mg}$ and Inj. Atropine $0.6 \mathrm{mg}$ respectively. The time for onset for two segment regression of sensory block and duration of sensory and motor block were recorded. The onset of sensory block was defined as the time between injection and loss of response to pinprick at T10 dermatome. The maximum level of sensory block was determined by pinprick every 
2 minutes. The duration of analgesia was taken as the time from intrathecal injection to first request of analgesics. The onset of motor block was assessed by Modified Bromage score. Patients were discharged from the recovery room when the motor block was completely resolved and when stable. Patients were also assessed for the occurrence of any adverse events like nausea, vomiting and pruritis.

\section{Results}

Demographic data such as: age, sex, age, height, weight and BMI and the block characteristics events were statistically analyzed. The $p$ value of $<0.05$ was considered to be statistically significant. The Demographic Variables of the patients are shown in the Table-1.

\begin{tabular}{|l|l|l|l|}
\hline & Group F & Group M & P value \\
\hline Age in years & $40.77 \pm 12.19$ & $40.55 \pm 8.05$ & 0.921 \\
\hline Weight(kg) & $61.90 \pm 8.05$ & $64.73 \pm 9.49$ & 0.217 \\
\hline Height(cm) & $161.57 \pm 8.23$ & $165.57 \pm 7.49$ & 0.100 \\
\hline Duration of surgery (min) & $72.83 \pm 14.78$ & $75.17 \pm 11.93$ & 0.504 \\
\hline BMI & $23.62 \pm 1.76$ & $23.49+2.17$ & 0.818 \\
\hline
\end{tabular}

There was no significant difference among the groups with respect to age, height, weight and duration of surgery. Maximum sensory level attained was comparable in both the groups and was between T6 and T8.

Comparison of block characteristics in the two groups:

\begin{tabular}{|l|l|l|l|}
\hline & Group M & Group F & P value \\
\hline Onset of sensory block ( in min) & $4.23 \pm 0.94$ & $2.92 \pm 0.81$ & $<0.001^{* *}$ \\
\hline Onset of motor block (in min) & $4.63 \pm 0.85$ & $3.30 \pm 0.79$ & $<0.001^{* *}$ \\
\hline 2 segment regression (in min) & $129.83 \pm 18.36$ & $100.83 \pm 12.18$ & $<0.001^{* *}$ \\
\hline Time for motor recovery (in min) & $252.33 \pm 27.03$ & $161.50 \pm 23.60$ & $<0.001^{* *}$ \\
\hline Duration of analgesia(in min) & $283.67 \pm 30.57$ & $196.00 \pm 23.21$ & $<0.001^{* *}$ \\
\hline
\end{tabular}

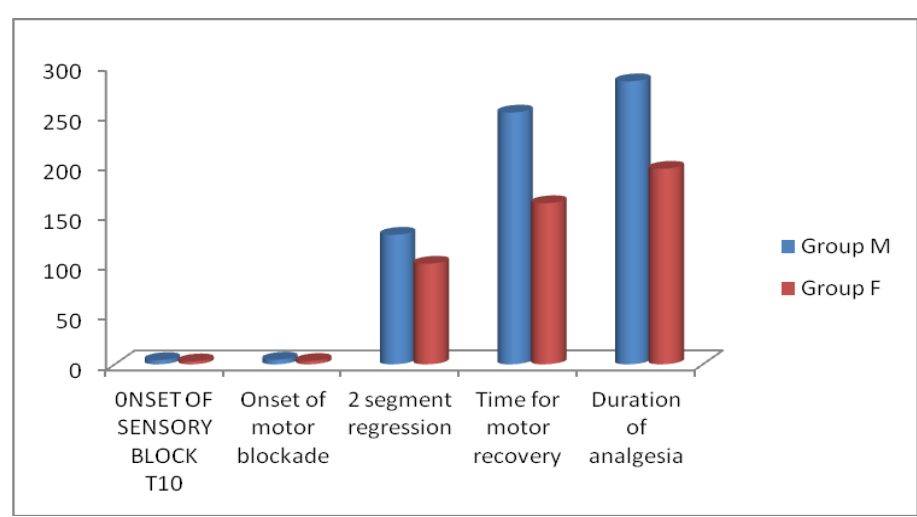

Onset and recovery of sensory and motor block was significantly shorter in group F than Group M. Duration of analgesia was also longer in group M $(283.67 \pm 30.57 \mathrm{~min})$ than with group F $(196 \pm 23.21 \mathrm{~min})$ $(\mathrm{P}<0.001)$.There was no significant difference in frequency of side effects in both the groups. No neurological deficit or other complication was observed in any patient. Haemodynamic parameters in the intra and post operative period were similar in both our study groups.

\section{Discussion}

Bupivacaine is an amide type local anesthetic, a racemic (50:50) mixture of $\mathrm{S}$ and $\mathrm{R}$ enantiomers. Since its introduction in 1956, it has been used as the drug of choice for spinal anesthesia due to its longer duration of action (3-7 hours), limited placental transfer, and minimal neonatal effects compared to other local anesthetics. In 1979, attention was drawn towards the cardiotoxic and neurotoxic effects of bupivacaine, linked to its Renantiomer. Another amide type local anesthetic, ropivacaine, the s-enantiomer of propyl derivative of pipecoloxylidide was first introduced in 1996 and approved for spinal anesthesia in the European union in $2004^{(1,2)}$. Ropivacaine, being a pure s-enantiomer, has low lipid solubility and blocks nerve fibres involved in pain transmission to a greater degree than those involved in motor function and is less cardiotoxic ${ }^{(3,4,5)}$

Central sensitization is an activity-dependent increase in the excitability of spinal neurons and is considered to be one of the mechanisms implicated in the persistence of postoperative pain. Magnesium sulfate acts by blocking the N Methyl D Aspartate channels in a voltage-dependent way to be improve the quality and 
duration of spinal anaesthesia. The magnesium sulfate safety profile has been documented by histopathological analysis in experimental studies ${ }^{(19)}$.The addition of intrathecal magnesium to intrathecal lipophilic opioid along with local anaesthetics led to delay in the onset of both sensory and motor blockade, along with an increase in the duration of spinal anesthesia. The duration of spinal anesthesia was found to be increased when magnesium was added to opioid with intrathecal local anesthetics compared with a combination of local anaesthetic and opioid mixture $(\mathrm{p}<0.001)^{(26)}$ The incidence of adverse events (hypotension, pruritis) was not increased by adding intrathecal magnesium. But it seemed that this drug was enough to provide effective anaesthesia.

Magnesium exerts its analgesic action as a non-competitive NMDA receptor antagonist, blocking ion channels in a voltage dependent manner ${ }^{(20,21,22)}$.This drug is both analgesic and anti - nociceptive additive drug. When used with local anaesthetic, it resulted in prolongation of analgesia without significant complication $(23,24)$. This prolongation of anaesthesia is consistent with the experimental synergistic action between spinal local aneasthetic and NMDA antagonists like magnesium sulphate, which use anti - nociceptive effects via different mechanisms; ${ }^{(25,26,27)}$ hence the rationale for combining the two. There are no selective NMDA receptor antagonists available for pain management; hence, drugs with other clinical uses, such as magnesium sulphate and ketamine, shown promises as analgesics, have been used. Magnesium sulphate is also known as nature's physiological calcium channel blocker. In animals, calcium channel blockers have demonstrated an anti - nociceptive effect and in chronic pain patients, they potentiate the effects of morphine. In the presence of intrathecal opioid, there is a beneficial effect, which may suggest that magnesium potentiates the effect of opioid. These findings correlate that with those of Kroin and colleagues ${ }^{(25)}$, who demonstrated that the addition of intrathecal $\mathrm{mg}$ increased the peak effect. Potentiating of opioid anti-nociception occurs by blocking the spinally mediated facilitatory component evoked by $\mathrm{C}$ fibre stimulation. This effect would be expected to continue in the postoperative period. The binding and dissociation of non competitive NMDA receptor antagonists is relatively slow, which may explain the continuation of anesthesia into the postoperative period and the requirement of reduction in the postoperative analgesics. It is possible that the solution to which magnesium sulfate added had a different PH, which might be the cause for delay in the onset of sensory and motor blockade. Fentanyl added to local anaesthetic agent seems to be the most frequently used combination to enhance and increase the duration of sensory analgesia without intensifying the motor blockade or delaying recovery from spinal anaesthesia. The dose of magnesium used in this study was based on data from Buvendraan et al, where $50 \mathrm{mg}$ of spinal magnesium sulfate potentiated fentanyl anti-nociception.In 1985,Lejuste, described the inadvertent intrathecal injection of $1000 \mathrm{mg}$ of $\mathrm{mg}$ so4, producing a dense motor block followed by complete resolution within $90 \mathrm{mts}$, with no neurological deficit at long term follow up.(29).A recent human study found no harmful effects of IT magnesium on spinal opioid analgesia in labour. Thus intrathecal MgSO4 seems to have a good safety profile. ${ }^{(20)}$

Thus an attempt was done to study the effects of addition of magnesium to the newer local anaesthetic ropivacaine with adjuvant fentanyl.

This analysis demonstrates that the addition of intrathecal magnesium to intrathecal lipophilic opioid fentanyl along with local anaesthetic. Ropivacaine leads to delay in the onset of both sensory and motor blockade but significantly prolongs the duration of sensory and motor block following spinal anesthesia. The duration of analgesia was also found to be increased with magnesium as adjuvant. The incidence of adverse events (hypotension, pruritis) were insignificant with intrathecal magnesium. This was consistent with the results of other studies ${ }^{(20,21,22,23)}$

Mitrajabalameli and Seyed Hamid Pakzadmoghadam et al compared effects of adding different doses of intrathecal magnesium sulfate for spinal anesthesia in the cesarean section and showed that all doses studied provide safe and effective anesthesia, but $75 \mathrm{mg}$ of this drug increases duration of postoperative analgesia and prolong than sensory and motor block without significant increase in maternal and neonatal side effects ${ }^{(20)}$.

Dayioğlu het al studied the effects of adding intrathecal magnesium sulfate $50 \mathrm{mg}$ to low-dose bupivacaine - fentanyl on the spread, duration, regression of spinal block, and postoperative analgesia in patients undergoing knee arthroscopy. They found that the addition of intrathecal magnesium (50 $\mathrm{mg})$ to spinal anesthesia prolonged the time for regression of two segments in the maximum block height and time to L2 regression, but did not affect maximum sensory level or the time to reach the highest level of sensory block. Even though the mean times to complete recovery of motor function were similar in the two groups, time to ambulation was significantly longer in the magnesium group than in the saline group. Total analgesic consumption in the first $24 \mathrm{~h}$ was not decreased significantly with the addition of magnesium to spinal anesthesia, but the time to first analgesic requirement was prolonged significantly ${ }^{(21)}$.

Khalili $\mathrm{G}$ et al evaluated the effect of additional magnesium sulfate $100 \mathrm{mg}$ to intrathecal isobaric $0.5 \%$ bupivacaine $3 \mathrm{ml}$ on spinal anesthesia in patients undergoing lower extremity orthopedic surgery and concluded that addition of $100 \mathrm{mg}$ intrathecal magnesium to $15 \mathrm{mg}$ bupivacaine without opioid supplement, prolonged the duration of the sensory block, decreased postoperative analgesic consumption, and significantly prolonged the onset of spinal anesthesia. ${ }^{(22)}$ 
Arcioni.R et al investigated whether supplementation of spinal anesthesia with combined intrathecally and epidurally infused MgSO4. reduced patients' post-operative analgesia requirements. They found that supplementation of spinal anesthesia with combined intrathecal and epidural magnesium sulphate significantly reduces patients' post-operative analgesia requirement ${ }^{(23)}$

In conclusion we found that isobaric $0.75 \%$ ropivacaine $(2.5 \mathrm{ml})$ with fentanyl 20 microgm along with $50 \mathrm{mg}$ Magnesium sulphate provided effective anesthesia for lower limb surgeries compared to ropivacaine with fentanyl alone.

\section{Conclusion}

The present study shows that addition of $50 \mathrm{mg}$ magnesium sulphate to $2.4 \mathrm{ml}$ of $0.75 \%$ isobaric ropivacaine with $20 \mu$ fentanyl delays the onset of sensory and motor blockade compared to only ropivacaine and fentanyl alone and shows that addition of intrathecal magnesium sulphate potentiates the action of opioid with local anesthetics when added intrathecally and prolongs the duration of block both sensory and motor.

\section{Acknowledgements:}

Sincere thanks to Dr. M. K. Radha, Head of the department, department of anaesthesiology, Adhichunchungiri institute of medical sciences and Dr. K. P. Suresh, Ph.D.Biostatistics, National Institute of Veterinary Epidemiology and Disease Informatics for their able guidance.

\section{References}

[1]. Wille M. Intrathecal use of Ropivacaine: a review. ActaAnaesth.Belg 2004; 55: 251 -59.

[2]. McClellan KJ, Faulds D. Ropivacaine: an update of its used in regional anesthesia. Drugs 2000;60:1065-93

[3]. Surjeet Singh, V.P. Singh, Manish Jain, Kumkum Gupta, BhavnaRastogi, SurbhiAbrolIntrathecal 0.75\% Isobaric Ropivacaine Versus 0.5\% Heavy Bupivacaine for Elective Cesarean Delivery: A Randomized Controlled Trial . J Pak Med Stud 2012;2:2

[4]. Gautier PE, De Kock M, Van Steenberge A, Poth N, LahayeGoffart B, Fanard L et al. intrathecalropivacaine for ambulatory surgery. Anesthesiology 1999; 91:1239-1245.

[5]. Kallio H, Sndll EV, Kero MP, Rosenberg PH. A comparison of intrathecal plain solutions containing ropivacaine 20 or 15 mg versus bupivacaine $10 \mathrm{mg}$. AnesthAnalg 2004; 99:713-717.

[6]. McNamee DA, Parks L, McClelland AM, Scott S, Milligan KR, Ahlen K et al. Intrathecalropivacaine for total hip arthroplasty total hip arthroplasty in total hip replacement; surgical reconstruction of the hip in which the ball-and-socket joint is replaced with a prosthesis. : double-blind comparative study with isobaric $7.5 \mathrm{mg}$ (ml.sup.-1) and $10 \mathrm{mg}$ ml-' solutions. Br J Anaesth 2002; 87:743747

[7]. Kallio H, Sndll EV, Tuomas CA, Rosenberg PH. Comparison of hyperbaric and plain ropivaeaine $15 \mathrm{mg}$ in spinal anaesthesia for lower limb surgery. Br J Anaesth 2004; 93:664-669.

[8]. NevalBoztug M D, ZekiyeBigut M D, Bilge kershim, Nurdansaykel M D, ErtugrulErtok M D. Comparison of Ropivacaine and Bupivacaine for intrathecal anesthesia during out patient arthroscopic surgery. Journal of Clinical Anaesthesia 2006; 18 : 521-25.

[9]. Gupta K, Singhal A B, Gupta P K, Sharma D, Pandey M N, Singh I. Ropivacaine: Anesthetic consideration in elderly patients for transurethral resection of prostrate a clinical trial. Anesthesia Essays \& Researches 2013; 7(2):178-82.

[10]. Nuray CE, Berrin G. A comparison of the effects of intrathecalropivacaineandbupivacaine during cesarean section. Turk J Med Sci 2011;41:219-81.

[11]. Eledjam JJ, Ripart J, Viel E. Clinical application of ropivacaine for the lower extremity. Curr Top Med Chem 2001;1:227-31.

[12]. Mantouvalou M, Ralli S, Arnaoutoglou H, Tziris G, Papadopoulos G. Spinal anesthesia: comparision of plain ropivacaine, bupivacaine and levobupivacaine for lower abdominal surgery. ActaAnaesthesiolBelg 2008; 59(2):65-71.

[13]. Kuthiala G, Chaudhary G. Ropivacaine: a review of its Pharmacology and Clinical use. Indian Journal of Anesthesia 2011; 55: 10410 .

[14]. Malinovsky J M, Charles F, Kick O, Lepage J Y, Malinge M, Cozian A, et al. Intrathecal Anesthesia: Ropivacaine Versus Bupivacaine: AnesthAnalg 2000; 91: 1457-60.

[15]. Lee YY, NganKee WD, Chang HK, So CL, Gin T. Spinal ropivacaine for lower limb surgery: A dose response study AnesthAnalg 2007; 105:520-3

[16]. Koltka K, Uludog E, Senturk M, Yavru A, Karadeniz M, Sengul T, Ozyalcin S. Comparison of equipotent doses of Ropivacainefentanyl and Bupivacaine-fentanyl in spinal anaesthesia for lower Abdominal Surgery. Anaesth Intensive Care Nov 2009; 37(6): 923-8.

[17]. Ozgurel O. Comparison of fentanyl added to ropivacaine or bupivacaine in spinal anesthesia. RegAnesth Pain Med 2003; (5 Suppl. 1),23:Abs 89.

[18]. Lee Y Y, NganKee W D, Muchhal K, Chan C K. Randomised double blind comparison of Ropivacaine-fentanyl and Bupivacainefentanyl for spinal Anaesthesia for urological surgery. ActaAnaesthesiolScand 2005;49:1477-82.

[19]. Xiao W H, Bennet G J. Magnesium suppresses neuropathic pain responses in rat via a spinal site of action .Brain Res 1994;666:168-72.

[20]. Jabulameli M, Pakzadmoghadam S H. Adding different doses of intrathecal Magnesium sulfate for spinal Anaesthesia in Cesarean section. Adv Biomed Res 2012;1:7.

[21]. Dayioglu H, Baykara ZN, Salbes A, Solak M, Toker K. Effects of adding magnesium to bupivacaine and fentanyl for spinal anesthesia in knee arthroscopy. J Anesth. 2009;23:19-25

[22]. Khalili G, Janghorbani M, Sajedi P, Ahmadi G. Effects of adjunct intrathecal magnesium sulfate to bupivacaine for spinal anesthesia: A randomized double-blind trial in patients undergoing lower extremity surgery. J Anesth. 2011;25:892-7

[23]. Arcioni R, Palmisani S, Tigano S, Santorsola C, Sauli V, Romanò S, et al. Combined intrathecal and epidural magnesium sulfate supplementation of spinal anesthesia to reduce post-operative analgesic requirements: A prospective, randomized, double-blinded controlled trial in patients with undergoing major orthopedic surgery. ActaAnesthesiol Scand. 2007;51:482-9

[24]. Ozalevli M, Cetin TO, Unlugence H, Guler T, Isik G. The effect of adding intrathecal magnesium sulphate to bupivacaine fentanyl spinal anaesthesia. ActaAnaesthesiol Scand. 2005;49:1514-9 [PubMed: 16223399]. 
[25]. Krion J S, McCarthy RJ, Von Roenn N, Schwab B, Tuman K J, IvanKovich A D. Magnesium sulfate potentiates morphine antinociception at the spinal level. AnesthAnalg 2000;90:913-7 [Pub Med:10735798]

[26]. Morrision A P, Hunter J M, Halpern S H, Banerjee A. Effect of intrathecal Magnesium in presence or absence of local anaesthetic with and without lipophilic opiods. British Journal of Anaesthesia March 2013;110(5):702-12.

[27]. Buvanendran A, McCarthy R J, Kroin J S, Leong W, Perry P, Tuman K J. Intrathecal Magnesium prolongs fentanyl analgesia: A Prospective, randomized, controlled trial. AnesthAnalg. 2002;95:661-6 [PubMed: 12198056].

[28]. Lejuste MJLR.Inadvertentintrathecaladministtration of magnesium sulphate. S Afr Med J 1985;68:367-8

[29]. Ronald D Miller. Millers Anesthesia, Elsevier Churchill LivingStone. 7th Edition, 2010; Chapter 27, Opiods, Page 814.

[30]. Robert K Stoelting, Simon C Hillier, Phamocology and Physiology in Anaesthetic Practice, Lippincott Williams and Wilkins, 4th Edition, 2006; Chapter 3, Opiod Agonists and Antagonists, Page. 90. Chapter 7, Local Anaesthetics, Page. 186. 